EGU21-10020, updated on 21 Apr 2021

https://doi.org/10.5194/egusphere-egu21-10020

EGU General Assembly 2021

(c) Author(s) 2021. This work is distributed under

the Creative Commons Attribution 4.0 License.

\title{
Understanding the relationship between environmental policies and deforestation activities in the Paraguayan Chaco
}

\author{
Monserrat Garcia Calabrese ${ }^{1}$, Shirley Salinas Romero ${ }^{1}$, Chynthya Cassacia Ibarrola ${ }^{1}$, Luis Morinigo ${ }^{1}$, \\ Magali Alvarenga ${ }^{1}$, and Emmanuel Da Ponte ${ }^{2}$ \\ ${ }^{1}$ National University of Asuncion, Faculty of Engineering, San Lorenzo, Paraguay, (Imorinigo@ing.una.py) \\ ${ }^{2}$ German Aerospace Center (DLR), Land Surface Dinamics (LAX), Wessling, Germany,(malvarenga@fiuna.edu.py)
}

Over the past 40 years, Paraguay has lost the majority of its natural forest cover, thus becoming one of the countries with the highest deforestation rates in the world. Uninterrupted deforestation practices in the Paraguayan Chaco between 1987 and 2012 resulted in the loss of 27\% of its original cover, accounting for almost $44,000 \mathrm{~km}^{2}$ of forested areas depleted. The rapid expansion of the agricultural frontier, cattle ranching, and illegal logging has converted the last forest remnants into isolated patches, thus endangering their continuity and biodiversity within them. In response to these events, the Paraguayan government has implemented numerous environmental programs and regulations to amend the damage that had happened in the past. Although governmental agencies claim a reduction in deforestation activities in the region, proper scientific environmental data that analyze the long-term effect of such regulations/programs remain scarce. Within this context, the present research analyzes the impact of local governments on changes occurred in Paraguayan Chaco forest between the years 1986 and 2020. Remote sensing data acquired from Landsat 4, 5, 7 and 8 images were used to derive the extent of the forest cover and deforestation rates over 34 years. Dynamics of the forest cover was correlated with each of the 10 government terms within the timeframe of the study. By analyzing the forest cover data during and after each term (around five years per government term), we sought to understand the influence of local policies on deforestation activities in the eco-region, aiming to identify social, political, and institutional drivers of change. A comprehensive assessment of creation and effectivities of protected areas, land concession to indigenous communities, and development/implementation of local policies and environmental laws are part of this study. Preliminary results show a significative difference on forest cover loss among governments terms ranging between $1 \%\left(2,385 \mathrm{~km}^{2}\right)$ and $9 \%\left(14,422 \mathrm{~km}^{2}\right)$. The lack of clear regulations, sound law enforcement, financial support, and inappropriate governance were initially identified as key drivers of change. The use of multi-temporal information was demonstrated to be a key component for designing, supporting, and monitoring conservation strategies and policies. It is crucial to consider not only the outlook of laws and policies aiming to halt deforestation activities but their actual influence on the behavior of natural resources over time. 